\title{
Mobile Emergency Care Service For Pregnant Adolescents: A Population-Based Study
}

\section{Cijara Leonice de Freitas}

Universidade Federal do Rio Grande do Norte Centro de Ciencias da Saude

José EleutérioJr.

Universidade Federal do Ceara Instituto de Ciencias do Mar Labomar

Ana K. Gonçalves ( $\square$ anakatherine_ufrnet@yahoo.com.br)

Universidade Federal do Rio Grande do Norte https://orcid.org/0000-0002-8351-5119

\section{Research article}

Keywords: pregnancy in adolescents, Mobile emergency care service, emergency treatment, adolescents, pregnancy complications, emergency medical services, adolescent health

Posted Date: January 2nd, 2020

DOI: https://doi.org/10.21203/rs.2.19803/v1

License: @ (i) This work is licensed under a Creative Commons Attribution 4.0 International License. Read Full License

Version of Record: A version of this preprint was published at International Journal of Gynecology \& Obstetrics on June 25th, 2020. See the published version at https://doi.org/10.1002/ijgo.13263. 


\section{Abstract}

Background MECS (Mobile Emergency Care Services) are used worldwide as an effective means to increase the chances of good prognosis in emergency cases, working with anything from trauma cases to unusual risk situations; they enablea reduction in mortality ratesand length of hospital stay. This study aimed to investigate obstetric occurrences in adolescents performed by MECS.

Methods This is a population-based study with 352 adolescent pregnant women (10 - 19 years old) treated by the public emergency mobile care system in a medium-sized city, Brazil. Descriptive analysis was performed using measurements of central tendency and dispersion of the numerical variables and the categorical variables, and using these measurements the frequency of occurrences was verified. Additionally, a two-stage cluster analysis was performed to identify divisions in the starting group based on the obstetric characteristics of pregnant women.

Results The prevalence of occurrences with adolescents was $28 \%$, corresponding to 352 of the 1258 pregnant women. Among the services provided to pregnant women, the average age of the patients was 17 yearsold $( \pm 1.53)$. The cluster analysis identified a segmentation of the sample divided into two groups, the first consisting of adolescents with gestational age (GA) over 36 weeks and presenting as main complaints: childbirth, inter-hospital transfer and hypertensive syndromes; and the second composed of patients with less than 36 weeks of GA who complained of hemorrhagic syndromes, premature birth and lower abdominal pain.

Conclusion MECS enable adequate and prompt care, which can reduce the consequences of complications for adolescent pregnant women and their babies, reducing mortality rates in developing countries.

\section{Background}

The Mobile Emergency Care Service (MECS) is characterized by assisting people in emergencies, whether clinical or traumatic [1]. In the scenes in which these events occur, the service prioritizes ensuring early and adequate care in the prehospital environment as well as access to the health system [2]. Due to the diversity and complexity of care, different types of occurrences can be identified, such as clinical, surgical, traumatic, psychiatric and obstetrics [3].

MECSs have been used worldwide as an effective means to increase the chances of good prognosis in emergency cases, from trauma cases (the most frequent emergencies) to situations of unusual risk pregnanciesand enable the reduction in mortality ratesand length of hospital stay [1, 2]. A study conducted in the Netherlands shows that MECS, allied with the assertive screening process, increased the chances of survival after a critical event [4].

In developing countries, such as India, Africa countries, and Brazil, obstetric emergencies demonstrate relevant numbers in mobile emergency care $[1,2]$. There is a scenario of constant discussion about the 
high rates of maternal death from preventable causes. Therefore, there is an expectation from the MECS to assist in a more agile and resolute way for these women.

Obstetric emergencies are situations that endanger the life of the pregnant woman and/or the fetus. Many studies indicate that these complications increase when they affect adolescent pregnant women, which may favor an increased risk of adverse maternal and neonatal events [5-6]. A study conducted in Latin America linked teenage pregnancy to premature birth, especially for younger teens aged between 13-15 years [7].

According to the World Health Organization, adolescents are individuals aged 10-19 years [8] who are in biological development, and this factor, combined with other extrinsic variables, such as poor socioenvironmental conditions, may influence the occurrence of adverse reproductive events. Thus, this study aimed to investigate obstetric occurrences with adolescents performed by MECS.

\section{Methods}

We conducted a population-base study between 2012-2015, with adolescent pregnant women attended by the public mobile emergency care system in the northern, southern, eastern, and western regions of a midsized city, in the Northeast Region of Brazil.

The research was approved by the Ethics Committee of the Federal University of Rio Grande do Norte (CAEE:30956414.0.0000.5292). According to the guidelines of Resolution 466/2012 of the National Health Council of Brazil, it is possible to waive the application of the Informed Consent Form (ICF) in cases where it becomes impossible to obtain this consent. In compliance with the resolution rules, we decided to waive the consent form in this study, given the characteristics of brevity, punctuality and urgency of care provided by MECS with pregnant women, as well as the lack of direct contact of researchers with patients, which were identified by letters and numbers in the bulletins to avoid identification, therefore, the data available in the service's information systems were assessed. Thus, the assent of pregnant women under 16 years of age or their guardians became unnecessary, however, it is emphasized that the precepts of reliability and privacy were respected.

As inclusion criteria, we used the concept of the World Health Organization, which considers adolescents to be individuals aged between 10 and 19 years.[8].

The data were collected from the Basic and Advanced Support Unitsof the Mobile Emergency Service Bulletins, registered by Nursing professionals and Physicians. Data collection was performed by two previously trained research assistants. This register of care contains user identification data such as name, address, and age; report of the pregnant woman's primary assessment such as type of care, obstetric conditions, parity, gestational weeks, and main complaints. These variables were organized in an electronic database, followed by correction and verification of possible typing errors by two researchers.

\section{Statistical analyses}


Data were exported and coded to Statistical Package for Social Sciences (SPSS Statistics for Windows, Version 24.0, Armonk, NY,IBM Corporation). The characterization of the sample was conducted through descriptive analysis of the data, using measurements of central tendency (mean and median) and dispersion (standard deviation) for numerical variables, while categorical variables were measured by frequency of occurrences and percentages were reported. Additionally, a two-stage cluster analysis was performed to verify the presence of segmentation in the starting group, based on the studied obstetric variables (miscarriage, gestational age, parity, cause).

\section{Results}

The prevalence of occurrences with adolescents was $28 \%$, corresponding to 352 of the 1258 pregnant women. The average age of the patients was $17 \pm 1.53$ years, of which $60(17 \%)$ were between 13 and 15 years old and $292(83 \%)$ between 16 and 19 years old (Table 1$)$.

A two-step cluster analysis identified a sample segmentation divided into two groups, the first consisting of adolescents with gestational age (GA) over 36 weeks and presenting as main complaints: childbirth, inter-hospital transfer, and hypertensive syndromes. In contrast, the second consisted of less than 36 weeks pregnant who complained of hemorrhagic syndromes, followed by premature birth and lower abdominal pain (Table 2).

Besides, the occurrence of previous spontaneous abortion was a fission variable, more prevalent in adolescents with less than 36 weeks of gestation (38.3\% versus $17.6 \%$ ). Our findings indicate a possible relationship between risky gestational age and hazardous conditions for mothers and fetuses, highlighting the hemorrhagic and hypertensive syndromes that were the leading causes of emergency care.

\section{Discussion}

Recent research indicates possible associations between adolescent pregnancy and adverse events such as pregnancy-induced hypertension (PIH), premature membrane rupture (PMR), anemia, postpartum hemorrhage (APH), and premature birth $[9,10]$. Regarding the risk of preeclampsia, this is not only higher in women aged 35 and over, but also in young women under 20 years of age [9-11].

In our study, preeclampsia mainly affected pregnant women with less than 36 gestational weeks, a fact that may increase the risk of maternal and neonatal morbidity and mortality. Therefore, the care provided by the MECS is relevant in situations such as these, which attempt to reduce the possible problems $[1,2$, 12].

Another factor that enables severe maternal morbidity is gestational hemorrhagic syndromes, which are preventable with proper treatment. The study by Paladugu RK and colleagues found that PMR and APH were significantly higher in adolescent mothers compared with adult mothers $(20 \%$ vs. $4 \%, p<0.05 ; 20 \%$ 
vs. $4 \%, p<0.05$, respectively) [13], similar results were observed in other studies by Yasmin et al in Madhya Pradesh and Talawar et al in India $[14,15]$.

Our data are similar to those cited since the leading cause of care in women with gestational age less than 36 weeks was gestational hemorrhagic syndromes. Thus, results found in this study can alert us to the growing risk of premature birth in adolescent pregnant women.

Premature birth is a relevant risk factor not only for pregnant women but also for the newborn, which can present complications such as low birth weight, respiratory distress, and malformations $[10,16]$. In our results, premature delivery was the second most frequent cause of emergency care in adolescent pregnant women with less than 36 weeks of gestation.

The association between hemorrhagic and hypertensive syndromes during pregnancy has been widely discussed, but both present severe complications which, when occurring concomitantly, may progress to potential complications that may result in maternal death $[17,19,20]$. Moreover, if these syndromes appear at separate and different stages in the pregnancy, they can contribute to the outcome of premature birth and thus cause health problems for the binomial $[18,20]$.

Additionally, these conditions become even more aggravating when they affect adolescent pregnant women, as these young women still have biological immaturity and are exposed to a hormonal environment altered by pregnancy that promotes maternal development at the expense of fetal well-being $[19,20]$.

\section{Conclusion}

To conclude, MECS should be a priority when it comes to emergency care, as this service enables adequate and prompt care, which can reduce the consequences of unfavorable and lethal complications for mothers and their babies, reducing mortality rates. What is more, multi-center studies involving larger populations may help to identify factors that increase obstetric risks, especially in higher-risk groups such as adolescents, and will thus provide more conclusive data.

\section{Abbreviations}

MECS - Mobile Emergency Service

$A G$ - gestational age

SPSS - Statistical Package for Social Sciences

WHO - World Health Organization

PIH - pregnancy-induced hypertension 
PMR - premature membrane rupture

$\mathrm{PPH}$ - postpartum hemorrhage

VS - VERSUS

\section{Declarations}

\section{Ethics approval and participation consent}

The present study was submittedfor approval to the Ethics Committee of the Federal University of Rio Grande do Norte, under registration number CAAE: 30956414.0.0000.5292. According to the guidelines of Resolution 466/2012 of the National Health Council of Brazil, it is possible to waive the application of the Informed Consent Form (ICF) in cases where it becomes impossible to obtain this consent. In compliance with the resolution rules, we decided to waive the consent form in this study, given the characteristics of brevity, punctuality and urgency of care provided by MECS with pregnant women, as well as the lack of direct contact of researchers with patients, which were identified by letters and numbers in the bulletins to avoid identification, therefore, the data available in the service's information systems were assessed. Thus, the assent of pregnant women under 16 years of age or their guardians became unnecessary, however, it is emphasized that the precepts of reliability and privacy were respected.

\section{Consent for publication}

Not applicable

\section{Availability of data and materials}

Data to support the findings of this study are available in the article and with the corresponding author upon reasonable request.

\section{Competing interests}

The authors declare that they have no competing interests.

\section{Funding}

This research did not receive any specific grants from funding agencies in the public, commercial or nonprofit sectors.

\section{Authors' contributions}

CLF contributed to the capture of data, design, and statistical analysis of the manuscript. AKG collaborated in the analysis and interpretation of the results, writing, and approval of the final version. JEJ collaborated inwriting and support of the final version 
None

\section{References}

[1] Sharma M, Brandler ES.Emergency medical services in India: the present and future.Prehosp Disaster Med. 2014; 29(3):307-10.

[2] Mould-Millman, Dixon, Sefa, et al. The State of Emergency Medical Services (EMS) Systems in Africa. Prehosp Disaster Med. 2017; doi:10.1017/S1049023X17000061.

[3] Wijesekera O, Reed A, Chastain OS , Biggs S, Clark EG, Kole T, Chakrapani AT, Ashish N, Rajhans P, Breaud AH, Jacquet GA.Epidemiology of Emergency Medical Services (EMS) utilization in four Indian emergency departments. Prehosp Disaster Med.2016;31(6):675-679.

[4] Andrew H, David C, Ting W, Yih N, Pin P, Swee L, Venkataraman A \& Marcus O. Prehospital Trauma Care in Singapore, Prehospital Emergency Care. 2015; 19:3, 409-415. https:// doi:

10.3109/10903127.2014.980477.

[5] Kirbas A, Gulerman HC, Daglar K, Pregnancy in Adolescence: Isit an obstetrical risk?. Journal of Pediatric and Adolescent Gynecology. 2016; doi: 10.1016/ j.jpag.2015.12.010.

[6] Kozuki et al.: The associations of parity and maternal age with small-for-gestational-age, preterm, and neonatal and infant mortality: a meta-analysis. BMC Public Health 2013;13 Suppl 3 :S2.

[7] Domínguez-Anaya R, Herazo-Beltrán Y. Age as a risk factor for complications arising during pregnancy in adolescents, Cartagena, Comlombia 2009: a cross-sextional study. Rev Colomb Obstet Ginecol. 2011;62:141-147.

[8]World Health Organization (WHO). Health for the World's Adolescents: A Second Chance in the Second Decade: Summary. Geneva,Switzerland:WHO Press; 2014.

[9] Duvan Ci, Turhan N, Onaran Y. Adolescent Pregnancies: Maternal and Fetal Outcomes. The New Journal of Medicine 2010; 27: 113-116.

[10] Khashan et al., Preterm birth and reduced birthweight in first and second teenage pregnancies: a register-based cohort study BMC Pregnancy and Childbirth 2010, 10:36.

[11] Nanneli P, Ulla E, Mika G,The impact of maternal obesity, age, pre-eclampsia and insulin dependent diabetes on severe maternal morbidity by mode of delivery-a register-based cohort study. Arch Gynecol Obstet. 2015; https:// doi: 10.1007/s00404-014-3352-z. 
[12] Singh et al. Transport of pregnant women and obstetric emergencies in India:na analysis of the '108' ambulance service system data.BMC Pregnancy and Childbirth. 2016; 16:318.

[13] Paladugu RK, Donipudi PC, Chimata D, Jasti M. Adolescent pregnancy and its outcomes: a crosssectional study. Int J Community Med Public Health 2018;5:4408-4414.

[14] Gazala Y, Aruna K, Bharti P. "Teenage Pregnancy - Its Impact On Maternal And Fetal Outcome".International Journal of Scientifi c Study. 2014;1:9-13.

[15] Talawar S, Venkatesh G. Outcome of Teenage Pregnancy. IOSR J Dental Med Sci. 2013;6:81-3.

[16] Thomas, E. G., Higgins, C. , Westgate, M. , Lin, A. E., Anderka, M. and Holmes, L. B. (2018), Malformations Surveillance: Comparison between Findings at Birth and Age 1 Year. Birth Defects Research, 110: 142-147. https:// doi:10.1002/bdr2.1096

[17] D. A. Schwartz. Maternal Death and Pregnancy-Related Morbidity Among Indigenous Women of Mexico and Central America. Global Maternal and Child Health: Medical, Anthropological, and Public Health Perspectives, https://doi.org/10.1007/978-3-319-71538-4_3

[18] Allanson et al.Causes of perinatal mortality and associated maternal complications in a South African province: challenges in predicting poor outcomes. BMC Pregnancy and Childbirth 2015; 15:37. https:// doi10.1186/s12884-015-0472-9.

[19] Cavazos-Rehg et al. Maternal age and risk of labor and delivery complications. Matern Child Health J. 2015;19:1202-1211.https:// doi:10.1007/s10995-014-1624-7.

[20] Wallace J. Young Maternal Age, Body Composition and Gestational Intake Impact Pregnancy Outcome:Translational Perspectives. In:L.R.Green, R.L.Hester, editores. Parental Obesity:Intergenerational Programming and Consequences, Physiology in Health and Disease.The American Physiological Society 2016.p.57-80.

\section{Tables}

Table 1. Obstetric description of pregnant women attended by MECS according to groups formed in clustering 


\begin{tabular}{l|l|l}
\hline & $\begin{array}{l}\text { Less than 36 weeks } \\
(\mathrm{N}=81)\end{array}$ & $\begin{array}{l}\text { More than 36 weeks } \\
(\mathrm{N}=125)\end{array}$ \\
\hline Age & $17.05 \pm 0.17$ & $17.10 \pm 0.13$ \\
\hline District & $\mathrm{N}(\%)$ & $\mathrm{N}(\%)$ \\
\hline North & $16(21.9)$ & $17(15.6)$ \\
\hline South & $3(4.1)$ & $2(1.8)$ \\
\hline West & $49(67.1)$ & $86(78.9)$ \\
\hline East & $5(6.8)$ & $4(3.7)$ \\
\hline Parity & $\mathrm{N}(\%)$ & $\mathrm{N}(\%)$ \\
\hline Primipara & $42(28.6)$ & $105(71.4)$ \\
\hline Multipara & $24(66.7)$ & $11(33.3)$ \\
\hline Spontaneous Abortion & $\mathrm{N} \mathrm{( \% )}$ & $\mathrm{N}(\%)$ \\
\hline No & & $105(66)$ \\
\hline Yes & $54(34)$ & $25(43.9)$ \\
\hline
\end{tabular}

Table 2. Description of the reason for occurrences attended by MECS according to groups formed in clustering

\begin{tabular}{l|l|l}
\hline Reason for occurrence & \multicolumn{1}{|c|}{$\begin{array}{c}\text { Less than 36 weeks } \\
(\mathbf{N}=\mathbf{8 1})\end{array}$} & $\begin{array}{c}\text { More than 36 weeks } \\
(\mathbf{N}=125)\end{array}$ \\
\cline { 2 - 3 } & $\mathrm{N}(\%)$ & $\mathrm{N}(\%)$ \\
\hline Hemorrhagic syndromes & $27(33.3)$ & $8(6.4)$ \\
\hline Hypertensive syndromes & $2(2.5)$ & $15(12)$ \\
\hline Clinical conditions & $5(6.2)$ & $2(1.6)$ \\
\hline Birth & $9(11.1)$ & $71(56.8)$ \\
\hline Premature birth & $13(16)$ & $2(1.6)$ \\
\hline Inter-hospital transfer & $5(6.2)$ & $18(14.4)$ \\
\hline External causes & $6(7.4)$ & $0(0)$ \\
\hline Contractions and pain & $13(16)$ & $4(3.2)$ \\
\hline Parturition & $0(0)$ & $3(2.4)$ \\
\hline Others & $1(1.2)$ & $2(1.6)$ \\
\hline
\end{tabular}

